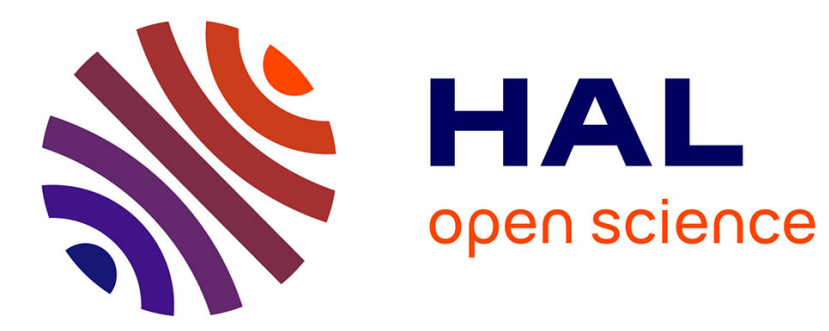

\title{
Profile of the liquid film wetting a channel
}

Janine Emile, Federico Casanova, Hervé Tabuteau, Olivier Emile

\section{- To cite this version:}

Janine Emile, Federico Casanova, Hervé Tabuteau, Olivier Emile. Profile of the liquid film wetting a channel. Applied Physics Letters, 2012, 100 (7), pp.074107. 10.1063/1.3685696 . hal-00909227

\section{HAL Id: hal-00909227 \\ https://hal.science/hal-00909227}

Submitted on 26 Nov 2013

HAL is a multi-disciplinary open access archive for the deposit and dissemination of scientific research documents, whether they are published or not. The documents may come from teaching and research institutions in France or abroad, or from public or private research centers.
L'archive ouverte pluridisciplinaire HAL, est destinée au dépôt et à la diffusion de documents scientifiques de niveau recherche, publiés ou non, émanant des établissements d'enseignement et de recherche français ou étrangers, des laboratoires publics ou privés. 


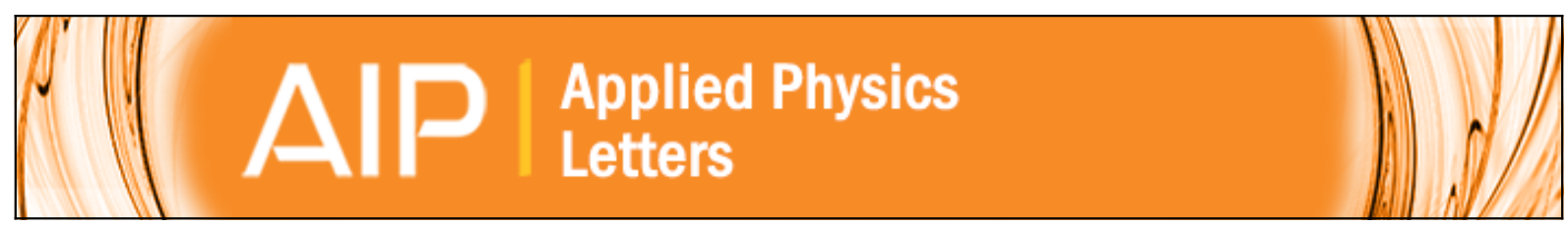

\section{Profile of the liquid film wetting a channel}

J. Emile, F. Casanova, H. Tabuteau, and O. Emile

Citation: Applied Physics Letters 100, 074107 (2012); doi: 10.1063/1.3685696

View online: http://dx.doi.org/10.1063/1.3685696

View Table of Contents: http://scitation.aip.org/content/aip/journal/apl/100/7?ver=pdfcov

Published by the AIP Publishing

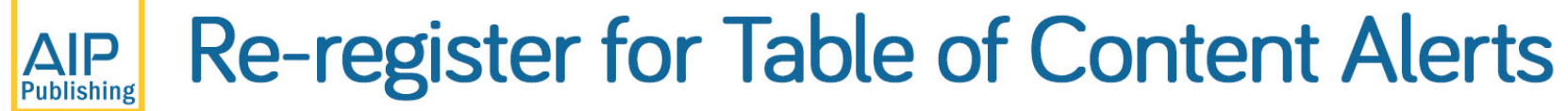

Create a profile.

Sign up today! 


\title{
Profile of the liquid film wetting a channel
}

\author{
J. Emile, ${ }^{1, a)}$ F. Casanova, ${ }^{1}$ H. Tabuteau, ${ }^{1}$ and O. Emile ${ }^{2}$ \\ ${ }^{1}$ IPR, UMR CNRS 6251, Université de Rennes I, 35042 Rennes Cedex, France \\ ${ }^{2}$ LPL, Université de Rennes I, 35042 Rennes Cedex, France
}

(Received 21 December 2011; accepted 30 January 2012; published online 16 February 2012)

\begin{abstract}
We have developed a simple optical technique to investigate the characteristics of liquid films wetting solid surfaces. To validate this technique, we have studied the wetting film that separates a train of lamellas moving through a channel. Total reflection of the laser beam on the wetting film/air interface is used to extract the profile and the thickness of the wetting film. For quasistatic movement of lamellas, we show that the thickness is well described by a capillary number power law. (C) 2012 American Institute of Physics. [doi:10.1063/1.3685696]
\end{abstract}

The liquid flow by foam bubbles and emulsions confined in milli/microchannels has received considerable attention, due to the fundamental and practical importance of this process in many engineering and medical applications. Theoretical and experimental studies are most of the time very complex because of the formation of a thin film (wetting film) on the solid walls. There is a considerable number of papers aimed at explaining the spreading and the dynamics of the wetting film (see, for review, Refs. 1-3). Landau and Levich $^{4}$ first predicted that the thickness $h$, of a film deposited on a solid and pulled vertically out of a liquid in the limit of small capillary number $C a$, follows the relation $h \sim C a^{\alpha}$ with $\alpha=2 / 3$. The dimensionless parameter $C a=\eta V / \gamma$ (V is the velocity of the solid, $\eta$ the liquid viscosity, and $\gamma$ the surface tension) links viscous and surface tension forces. Taylor ${ }^{5}$ found that a $C a^{1 / 2}$ behavior describes the deposition of a liquid film formed in slug flow in a capillary tube. At the same time, Bretherton ${ }^{6}$ performed a theoretical analysis, giving a $\mathrm{Ca}^{2 / 3}$ law for long bubbles. The nature of the surfactant used was considered latter, ${ }^{7}$ with the powerlaw index $\alpha$ depending on the surface rheology. Optical interferometry methods have been developed to measure the shape and the thickness of liquid films. Various geometries such as a liquid film intercalated between two specific materials $^{8,9}$ or the spreading of a liquid on a substrate ${ }^{10,11}$ have been adopted. Measurements of liquid film profiles in channels under adiabatic condition have also been performed, ${ }^{12,13}$ mainly dedicated to the study of long bubbles in different flow regimes. However, only few experimental observations on the wetting film during the flow of aqueous foams through channels have been published. One challenge is to extract a high quality signal from the channel one by minimizing such problems of surface roughness and optical absorption of the walls. Here, in the simple geometry of a periodic train of lamellas (vertical bubble films) in the case of a dry foam (negligible liquid fraction), we propose a simple optical technique to simultaneously measure the profile and the thickness of the wetting film (from $100 \mathrm{~nm}$ to $1 \mathrm{~mm}$ ).

We used a T-junction geometry to produce a periodic train of bubbles. We first produce a positive mold in NOA 81 (Norland Products), a UV-curable negative resist, patterned on a glass plate, following the open-faced methodology. ${ }^{14}$

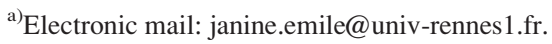

The polydimethylsiloxane (PDMS) is then poured over the mold, cured at $75^{\circ} \mathrm{C}$ for an hour and peeled from the mold. Finally, the PDMS mold is plasma bonded onto a glass plate. Both inlets of the $\mathrm{T}$-junction have a $0.5 \mathrm{~mm}$-height and a $1 \mathrm{~mm}$-width. The T-junction is followed by a straight channel with a $5 \mathrm{~mm}$-cross section. This last part of the device is used to ease the visualization of the lamellas produced in the T-junction. Air is used as the gas phase and is injected by a syringe pump (Harvard PHD) with a $4 \mathrm{ml} / \mathrm{min}$-flow rate. As the continuous phase, which is also controlled by a syringe pump with a $0.1 \mathrm{ml} / \mathrm{min}$-flow rate, we use solutions of $5.4 \%$ sodium lauryldioxyethylene sulfate (SLES, $55.6 \mathrm{~g} / \mathrm{L}$, Cognis) in pure water. In these flow conditions, the lamellas are equally spaced $(6 \mathrm{~mm})$. The outlet of the PDMS channel is connected to a home-built glass straight channel with a $3 \mathrm{~mm}$-height (below the capillary length) and a $4 \mathrm{~mm}$-width. To build this channel, we used optical quality glass plates (BK7, thickness $2 \mathrm{~mm}$ ) glued by an optical UV adhesive (NOA 81). One channel end is left at the atmospheric pressure, whereas the other is connected to a syringe pump to push or pull the lamellas by a constant air flow in the 1-7 $\mathrm{ml} / \mathrm{min}$-range. The motion of the lamellas, at a constant velocity $\mathrm{V}$ in the range $1.4-8.5 \mathrm{~mm} / \mathrm{s}$ (corresponding to $9 \times 10^{-4}-5 \times 10^{-3} \mathrm{Ca}$ values), is recorded as a function of time using a video camera. All experiments are performed at a controlled temperature $T=20.0 \pm 0.5^{\circ} \mathrm{C}$, and the glass channel is cleaned with Hellmanex (Sigma-Aldrich, diluted 10 times in pure water), ethanol (99\%), acetone (99.5\%), and rinsed with pure water after each experiment.

To measure the wetting film thickness, a BK7 right angle prism $(5 \mathrm{~mm})$ is attached to the channel wall using glycerol. Since glycerol has the same refractive index as the glass used $\left(n_{g}=1.51\right)$, this ensures optical contact between the prism and the channel wall. A green laser (beam waist $360 \mu \mathrm{m}, \lambda=532 \mathrm{~nm}$ ) impinges at nearly normal to the prism and then gets totally reflected on the glass/air interface, since the angle of incidence $\theta$ is greater than the critical angle a sin $\left(1 / n_{g}\right)$ (see Fig. 1). When the wetting film is deposited, the laser beam is refracted on the glass/wetting film interface, travels through the film and gets totally reflected on the wetting film/air interface. Since the laser beam impinges on the glass/wetting film interface with an angle $\theta=45^{\circ}$, the optical path of the laser beam through the wetting film results in a shift $x$ that is recorded on a position sensitive detector 


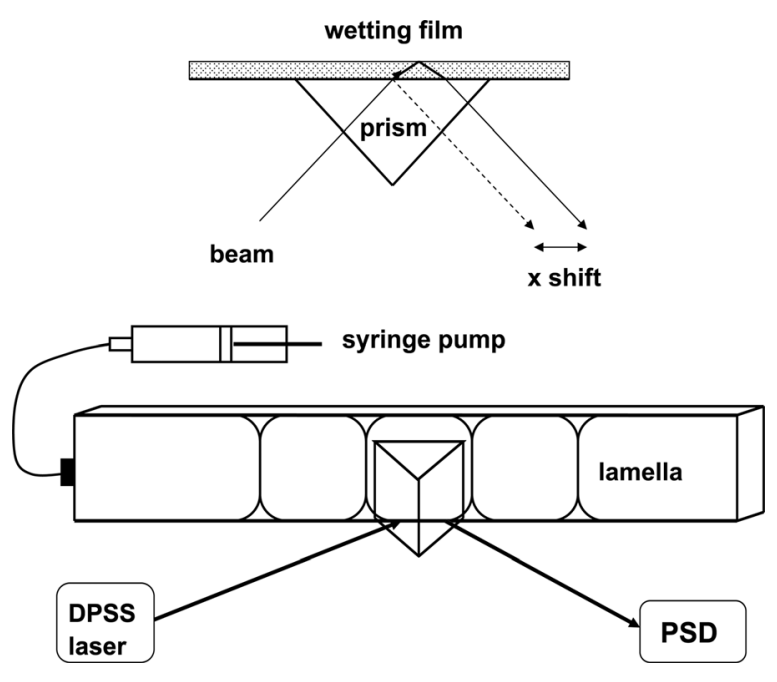

FIG. 1. Experimental set-up. Lamellas are pushed or pulled using a syringe pump. The thickness of the wetting film is probed by a laser at total internal reflection. The shift of the beam due to the film thickness is recorded on a PSD.

(PSD, Thorlabs, PDP90A). Note that the partial reflection on the glass/wetting film interface is at most equal to $2 \%$ of the intensity and that the so-called Goos-Hänchen ${ }^{15}$ shift on the glass/air interface and the wetting film/air interface compensate for each others, and thus, these two effects are neglected. The thickness of the wetting film $h$ can be easily deduced from the shift $x$ by the following equation: $h=\left[\left(\frac{n_{w}}{n_{e}}\right)^{2}-\sin ^{2} \theta\right]^{1 / 2} x$, where $n_{w}$ is the refractive index of the wetting film $\left(n_{w} \approx 1.33\right)$ and $h=0.525 x$. In order to improve the resolution of our detection system, we have modulated the laser beam with a mechanical chopper (Thorlabs MC1000) at $500 \mathrm{~Hz}$ and we used a lock-in amplifier (Stanford SR830) before recording DC signals using LabVIEW. This leads to a resolution of the shift of $0.12 \mu \mathrm{m}$.

Figure 2 represents an example of raw data of the voltage signals, for a train of four equally spaced lamellas. We have shown on this figure both the total signal recorded on the PSD and the signal corresponding to the shift $x$. Each pass of the lamella along the channel wall near the prism induces a drop of the voltage signals since the laser beam is not at total reflection any more. The decrease of the drop is due to a deformation progressively weaker through the train of correlated lamellas. Depending on the push-pull action of the syringe pump, the lamella numbered 1 is the most distorted. If the lamellas are widely separated and uncorrelated, the drop of the voltage signals is constant and the wetting film is not detectable within the resolution of the PSD. The deflection of the laser beam via the differential signal simultaneously gives information on the shape and the thickness of the wetting film. When the lamellas are pushed, the positive $x$ shift on Fig. 2 corresponding to the back side of the lamella goes down to a negative value which is related to the front side of the next lamella. The signs of the shift are reversed when the lamellas are pulled. Since the surface of the wetting film is not always parallel to the channel wall, there may also be an angular shift of the beam. In order to discriminate between the two effects, the PSD is positioned at different distances from the channel (from $9.3 \mathrm{~cm}$ to $93 \mathrm{~cm}$ ). At a given position of the film, the variation of the $x$ shift versus the distance of the PSD must lead to a straight line whose slope is related to the curvature of the interface wetting film/air over the channel walls and its ordinate corresponds to the thickness.

To avoid any edge effect and to ensure the symmetry of the profile of the wetting film on both sides of the lamellas (Fig. 3), we have chosen to study the film between the lamellas numbered 2 and 3 (Fig. 2(b)). When the lamella is pushed or pulled, one observes slight differences on the shape of the wetting film, that may be related to the infuse and withdraw capabilities of the syringe pump. The angle between the wetting film/air interface and the channel wall is estimated to be about $\pm 1 \times 10^{-5} \mathrm{rad}$. This average value decreases from the lamella 1 to the lamella 4 (from $\pm 1 \times 10^{-4}$ to $\pm 1 \times 10^{-6}$ $\mathrm{rad}$ ), due to the progressive deformation through the train (as mentioned in the previous paragraph). However, using this set-up, it is not possible to measure the contact angle surrounding the wetting film and the meniscus near the lamella. Indeed, due to the lamella, the deflection of the beam is too important for the detection range of the PSD.

The thickness evolutions of the wetting film with $\mathrm{Ca}$, for different distances between the lamellas, are reported in Fig. 4. For small $\mathrm{Ca}$ numbers, regardless of the position between the lamellas, the thickness is well described by a power law with a $3 / 2$ exponent. No theoretical model predicts this exponent. In order to check whether this power law dependence is due to the surfactant, we used instead sodium dodecyl sulfate (SDS, $12 \mathrm{~g} / \mathrm{L}$, Sigma-Aldrich). Of course, for
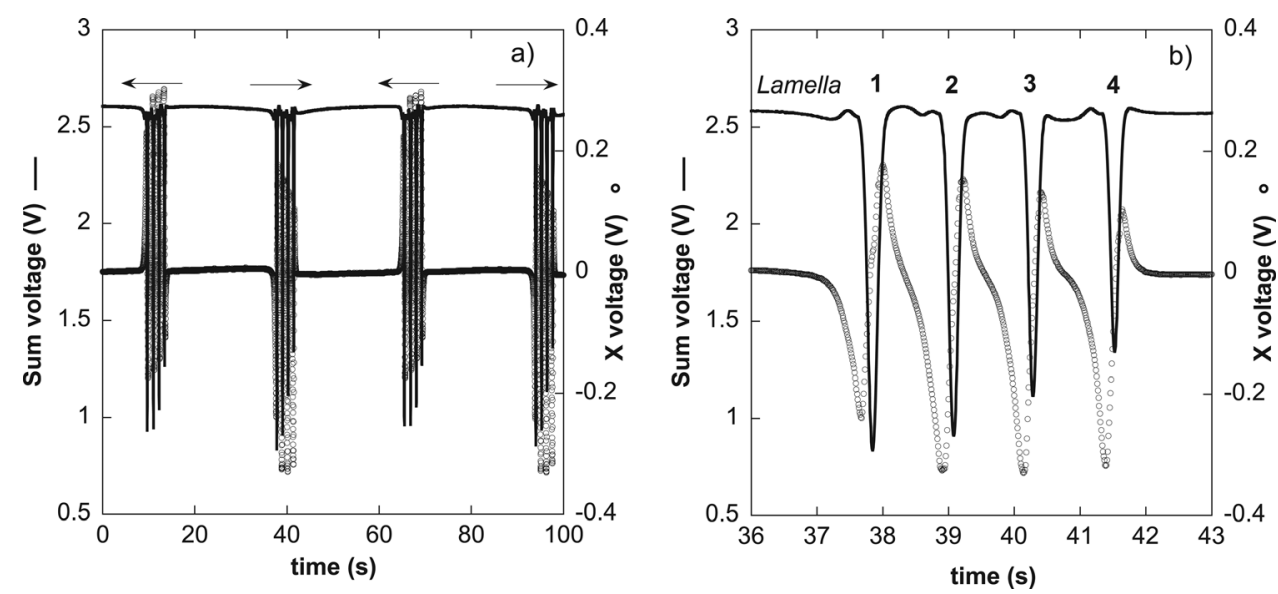

FIG. 2. (a) Typical signals recorded from the PSD for a train of four lamellas spaced by $6 \mathrm{~mm}$ pushed at a $5 \mathrm{~mm} / \mathrm{s}$ velocity. The arrows show the back and forth motions corresponding to the pushpull action of the syringe pump. (b) Zoom of the spectrum. The black lines and circles correspond, respectively, to the total and differential signals. 

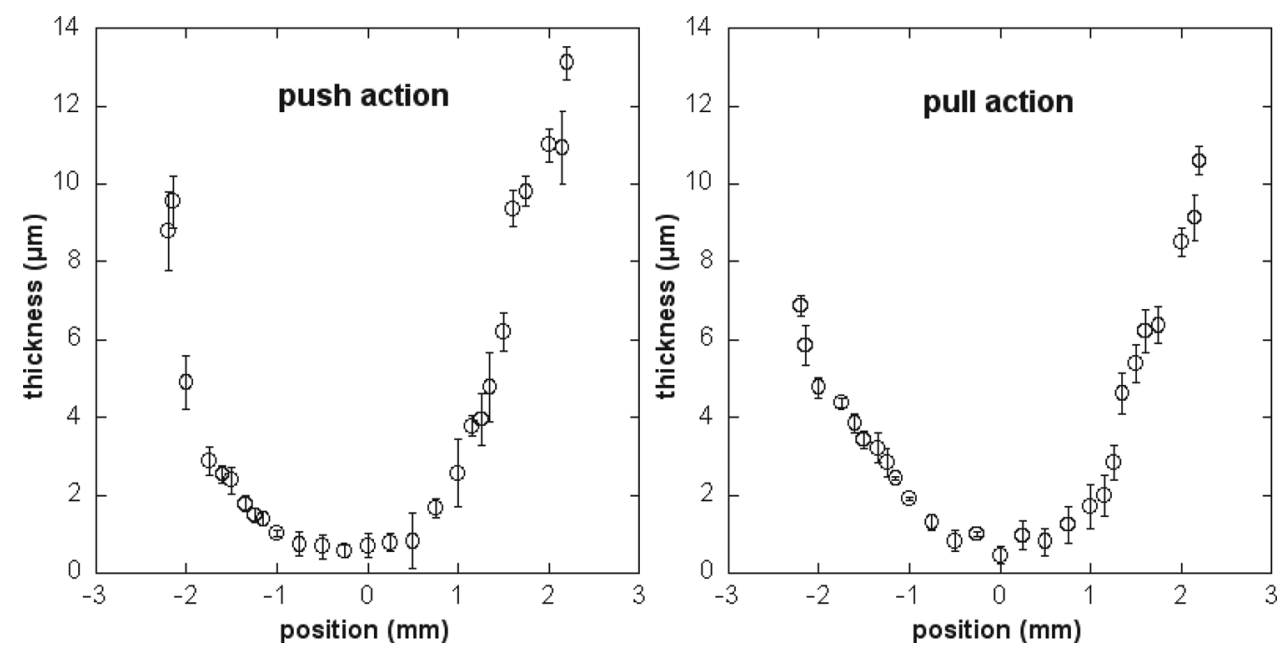

FIG. 3. Shapes of the SLES wetting film when the lamella train is pushed and pulled at a $5 \mathrm{~mm} / \mathrm{s}$ velocity. this surfactant, since the bulk viscosity is lower $\left(3.6 \times 10^{-3}\right.$ Pa s compared with $18.6 \times 10^{-3} \mathrm{~Pa}$ s for SLES), the power law holds for a range of $\mathrm{Ca}$ numbers which is ten times smaller. However, it seems that the phenomenon and, thus, the power law variation do not depend on the physical chemistry of our foaming solutions. In this quasistatic regime, the meniscus connecting the lamella to the wall keeps the same basic shape, without distortion profile, and the thickness of the lamella is unchanged during stretching. Actually, the lamella thickness (about $700 \mathrm{~nm}$ ) has been measured by transmission, using another laser interferometer. ${ }^{16}$ The liquid volume fraction of the studied foam is low $(\simeq 9 \%)$. Our geometry is very different from that traditionally used in the study of long bubbles moving in a tube filled with liquid. ${ }^{6}$ Nevertheless, our device to produce foam bubbles could be adapted to make a wet foam with at least one liquid fraction above $15 \%$. Preliminary measurements show that the exponent defined in the power law of the wetting film thickness changes from $3 / 2$ to $2 / 3$ for very wet foams $(\simeq 50 \%)$. Such

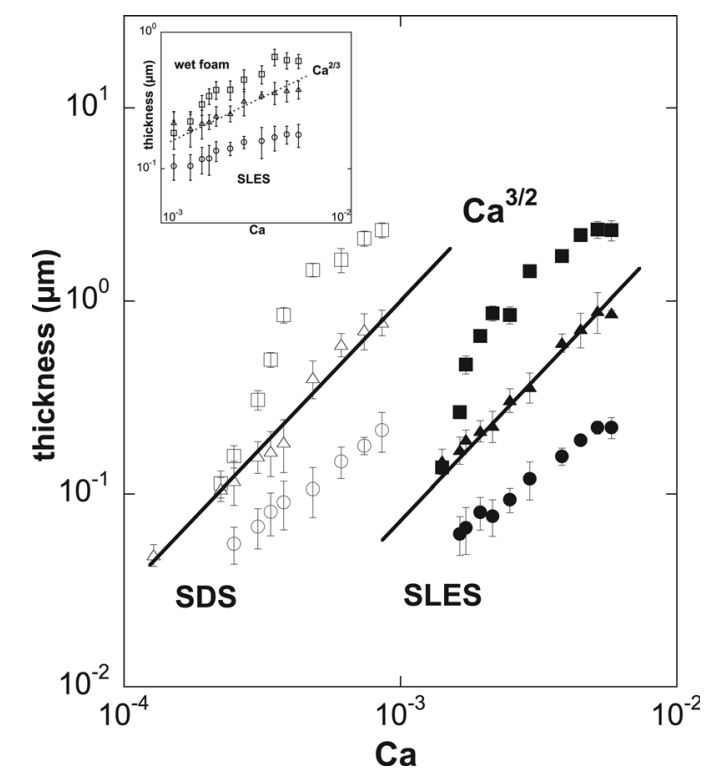

FIG. 4. Thickness evolutions of SDS and SLES wetting films vs. $\mathrm{Ca}$, for a train of lamellas spaced by $6 \mathrm{~mm}: 0 \mathrm{~mm}$ that corresponds to the middle in between the lamellas (circles), $+1 \mathrm{~mm}$ (squares), and $-1 \mathrm{~mm}$ (triangles). Insert: Example of a very wet foam. transition requires extensive experiments by controlling the liquid fraction.

In conclusion, we have developed an optical technique that is well suited for the study of films wetting smooth, planar, and transparent surfaces. In particular, we have shown that this technique gives access to the film thickness with a fine resolution. We used a laser beam totally reflected on the wetting film/air interface thanks to a right angle prism settled on a glass plate. In the particular case of a periodic train of lamellas (geometry of a dry foam), we have studied the dynamics of the wetting film between two lamellas. Whatever the physical chemistry of foaming solutions and the liquid fraction, we have demonstrated that its thickness is well defined by a power law of the capillary number. This optical method turns out to be a powerful tool to investigate thin liquid films. Various applications in milli or microfluidic manipulation may include both the transport of foams and emulsions in confined geometries and the spreading of a nanofluid film on a solid substrate.

We would like to thank P. Chasle and A. Faisant for technical assistance.

${ }^{1}$ P. G. de Gennes, Rev. Mod. Phys. 57, 827 (1985).

${ }^{2}$ G. F. Teletzke, H. T. Davis, and L. E. Scriven, Rev. Phys. Appl. 23, 989 (1988).

${ }^{3}$ P. G. de Gennes, F. Brochard-Wyart, and D. Quéré, Capillarity and Wetting Phenomena: Drops, Bubbles, Pearls and Waves (Springer, New York, 2003).

${ }^{4}$ L. Landau and B. Levich, Acta Physicochim. URSS 17, 42 (1942).

${ }^{5}$ G. I. Taylor, J. Fluid Mech. 10, 161 (1961).

${ }^{6}$ F. P. Bretherton, J. Fluid. Mech. 10, 166 (1961).

${ }^{7}$ N. D. Denkov, S. Tcholakova, K. Golemanov, V. Subramanian, and A. Lips, Colloids Surf., A 282-283, 329 (2006).

${ }^{8}$ P. Martin and F. Brochard-Wyart, Phys. Rev. Lett. 80, 3296 (1998).

${ }^{9}$ G. Xie, J. Luo, D. Guo, and S. Liu, Appl. Phys. Lett. 96, 043112 (2010).

${ }^{10}$ A. A. Darhuber, S. M. Troian, J. M. Davis, S. M. Miller, and S. Wagner, J. Appl. Phys. 88, 5119 (2000).

${ }^{11}$ A. Nikolov, K. Kondiparty, and D. Wasan, Langmuir 26, 7665 (2010).

${ }^{12}$ T. Ohyama, K. Endoh, A. Mikami, and Y. H. Mori, Rev. Sci. Instrum. 59, 2018 (1988).

${ }^{13}$ Y. Han, N. Shikazono, and N. Kasagi, Int. J. Multiphase Flow 37, 36 (2011).

${ }^{14}$ C. Harrison, J. T. Cabral, C. M. Stafford, A. Karim, and E. J. Amis, J. Micromech. Microeng. 14, 153 (2004).

${ }^{15}$ F. Goos and H. Hänchen, Ann. Phys. 1, 333 (1947).

${ }^{16}$ J. Emile, F. Casanova, G. Loas, and O. Emile, "Swelling of foam lamella in a confined channel" (unpublished). 